\title{
Lisboa e Buenos Aires na poesia de Cesário Verde e Evaristo Carriego: uma primeira aproximação.
}

Claudio Celso Alano da Cruz

Universidade Federal de Santa Catarina

RESUMO: BUSCA-SE AQUI UMA APROXIMAÇÃO ENTRE CESÁRIO VERDE E EVARISTO CARRIEGO, DOIS POETAS REPRESENTATIVOS DO MOMENTO EM QUE SUAS RESPECTIVAS CIDADES, LISBOA E BUENOS AIRES, PASSAVAM POR UM PROCESSO DE EXPANSÃO E MODERNIZAÇÃO URBANA. CABERIA A CESÁRIO VERDE E CARRIEGO REPRESENTAR AS TRANSFORMAÇÕES EM SUAS CIDADES, COM NÃO POUCAS IDENTIDADES POÉTICAS, ENTRE AS QUAIS MERECE DESTAQUE UM FORTE REALISMO POÉTICO, QUE BUSCA EXTRAIR O LIRISMO DAS RUAS, DO RÉS-DO-CHÃO, DO COTIDIANO, ENFIM. MAS TAMBÉM SÃO DESTACADAS ALGUMAS DIFERENÇAS SIGNIFICATIVAS, ENTRE ELAS O FATO DO PRIMEIRO PRIVILEGIAR AS ZONAS CENTRAIS DA METRÓPOLE, ENQUANTO O POETA ARGENTINO REPRESENTOU EXCLUSIVAMENTE AS ÁREAS PERIFÉRICAS, AS ENTÃO CHAMADAS ORILLAS BUENAIRENSES.

ABSTRACT: THIS ARTICLE INTENDS TO MAKE A COMPARATIVE READING OF CESÁRIO VERDE'S AND EVARISTO CARRIEGO'S POEMS. BOTH POETS CREATED STRONG URBAN REPRESENTATIONS. IN THEIR WORKS, LISBON AND BUENOS AIRES APPEAR JUST IN THE MOMENT OF THEIR INCREASING AND MODERNIZATION PROCESS, FOLLOWING THE PARISIEN MODEL, WHICH IS REPRESENTED IN BAUDELAIRE'S POEMS. THIS COMPARATIVE READING FOCUSES NOT ONLY SIMILARITIES BETWEEN THE TWO POETIC WORKS (ONE OF THEM, PERHAPS THE MOST IMPORT, CAN BE CONSIDERED THE CREATION OF A "POETIC REALISM"), BUT ALSO IMPORTANT DIFFERENCES BETWEEN THEM, LIKE THE FACT THAT WHILE CESÁRIO VERDE REPRESENTED THE CENTRAL URBAN ZONE, CARRIEGO WAS THE POET OF BUENOS AIRES' ORILLAS.

PALAVRAS-CHAVE: CESÁRIO VERDE; CARRIEGO; POESIA URBANA; REALISMO; CENTRO; PERIFERIA.

KEY-WORDS: CESÁRIO VERDE; CARRIEGO; URBAN POETRY; REALISM; CENTRAL URBAN ZONE; SUBURB. 
asta el siglo XIX no era común que un poeta utilizara una ciudad como tema", afirma Horacio Salas em La poesía de Buenos Aires (SALAS,1968, p.11). Podese ir mais longe e dizer que a poesia urbana enquanto tal é uma invenção daquele século XIX, uma invenção do que costumamos chamar de capitalismo moderno. Por isso que falar em poesia urbana quase que se confunde com falar em poesia urbana moderna, ou seja, uma espécie particular de poema que procura representar a cidade moderna ou que está em vias de se transformar em moderna. Neste sentido, seria natural que os primeiros poemas urbanos surgissem no país que estivesse à frente na implantação daquele referido capitalismo. E foi exatamente o que aconteceu. Londres, capital da Inglaterra, seria a primeira cidade moderna a servir de tema a seus poetas, entre os quais caberia citar os pioneiros Blake e Wordsworth. Nos primórdios do século XIX já estavam eles criando - no sentido forte da expressão - poesia urbana, ou seja, estavam inventando uma Londres literária moderna. Mas, como se sabe, além da Inglaterra, havia também um outro país que dividia com ela a liderança daquele capitalismo, a França. França cuja capital era Paris, a grande rival de Londres durante todo o século. E foi representando essa Paris, já em meados do século XIX, que o poeta Charles Baudelaire iria se estabelecer como o modelo maior na criação desse subgênero que estamos chamando de poesia urbana. $\mathrm{O}$ fato de que o mesmo Charles Baudelaire também veio a se estabelecer como "o pai da poesia moderna" só reforça a idéia do quanto cidade e modernidade estão vinculadas.

Quero agora retomar o livro de Horacio Salas, já que a intenção aqui é aproximar o que ficou comumente conhecido como o "primeiro cantor do arrabalde portenho" - mas que, mais propriamente, podemos chamar de "primeiro cantor de Buenos Aires", o seu primeiro poeta urbano - com aquele que seria o seu equivalente na cidade de Lisboa. Aquele que, como disse o também poeta David Mourão-Ferreira, "nos ensinou a ver a cidade". Estou falando de, respectivamente, Evaristo Carriego (1883-1912) e Cesário Verde (1855-1886).

A diferença de geração, na verdade, naquilo que aqui interessa, ainda mais os aproxima, já que o período em que viveram correspondeu a um momento muito especial na cidade onde atuaram, ou seja, quando Lisboa e, logo depois, Buenos Aires, estavam dando o "salto" para a modernidade. Como era comum no tempo, a modernização urbana da Paris da década de 1850 repercutiria na Lisboa de 1870 e na Buenos Aires em torno de 1900. 
Como praticamente todos os líricos modernos, Evaristo Carriego e Cesário Verde descendem de Baudelaire. E mais ainda poetas como eles, porque são dos que se preocuparam particularmente em registrar suas vivências na cidade. Criaram poemas que constituem exemplos acabados do que chamamos acima de poesia urbana. Estabeleceram vínculos muito evidentes com o livro Les fleurs du mal (1857) e de modo especial, com uma de suas seções, qual seja, a denominada “Tableaux parisiens" ("Quadros parisienses"). Pode-se afirmar que, cada um a sua maneira, criaram um conjunto de poemas que poderiam também ser chamados de "quadros". No caso de Evaristo, "quadros portenhos", no de Cesário, "quadros lisboetas".

Quanto a Carriego, convém deixar claro de início que levaremos em conta apenas os poemas daquela que a crítica tem chamado de sua segunda fase, dedicada a representar o bairro de Palermo, então uma zona periférica de Buenos Aires. E ao dizer isso, convém esclarecer também que, ao contrário de Cesário, o poeta argentino não dedicará um verso sequer às zonas centrais da cidade que se modernizava, mas estará muito atento às suas chamadas orillas, às zonas marginais da cidade, que também se encontravam em crescimento acelerado. Um crescimento, no entanto, muito diverso daquele ocorrido no chamado Centro.

Já no caso de Cesário, embora o sujeito lírico faça eventuais menções a lugares suburbanos, o principal da sua representação citadina diz respeito às zonas centrais de Lisboa. Ainda em relação ao poeta português, cabe destacar que só nos ocuparemos da sua vertente urbana, deixando na sombra seus poemas dedicados ao campo e que foram escritos e publicados de forma mais ou menos paralela aos urbanos, conforme tem sido destacado por seus comentadores. Assim, não nos preocupará aqui uma das temáticas centrais de Cesário, qual seja, o contraste campo-cidade, até porque isso inexiste em Carriego, já que toda a sua produção literária foi estritamente urbana, mais particularmente, suburbana. Jamais escreveu uma linha sequer voltada ao campo. Não deixa de ser surpreendente, diga-se de passagem, que, já naquela época, um poeta ignorasse tão completamente o campo, num país como a Argentina onde, até hoje, ele tem uma considerável importância.

Comecemos essa aproximação destacando algumas semelhanças de ordem biográfica. Ambos morreram jovens, mas não tão jovens que não pudessem legar à posteridade uma obra que, mesmo pequena, tivesse a marca inequí- 
voca de uma maturidade poética e existencial. Cesário morreu aos 31 anos, Carriego aos 29, ambos de tuberculose. Neste sentido, pareceriam dois típicos poetas românticos, com uma biografia propícia à mistificação popular, o que irá ocorrer em parte com o poeta argentino. Os dois autores começam a publicar em torno dos 20 anos, em jornais e revistas, poemas que serão posteriormente reunidos em volume póstumo por amigos literatos e com o decidido apoio dos respectivos irmãos.

No caso de Cesário, a tarefa coube ao amigo Silva Pinto, que editou, um ano após a morte do poeta, e com a ajuda do irmão Jorge Verde, o que ficou conhecido como O Livro de Cesário Verde, reunindo 22 poemas, aos quais se agregariam posteriormente mais 18 composições. Isso é tudo que nos ficou da obra poética de Cesário Verde. Mas esse pouco foi o suficiente para, com o tempo, introduzir na literatura portuguesa modificações substanciais, abrindo caminho para a modernidade poética em Portugal. Não por acaso, um dos célebres heterônimos pessoanos chamou-o de "mestre Cesário Verde".

No caso de Evaristo Carriego, ele ainda conseguiu editar em vida o livro Misas herejes, ao reunir em 1908 o que vinha publicando na imprensa portenha desde 1903 e, claro, mais alguns inéditos. No entanto, como quase toda a crítica tem apontado, apenas cerca de 10 dos 47 poemas que compõem o livro podem ser considerados efetivamente carreguianos, significando isso que todos os outros seriam nada mais do que simples diluição parnaso-simbolista (modernista, no âmbito hispano-americano), frutos epigônicos de um Ruben Darío ou Leopoldo Lugones. O que realmente teria garantido a permanência do seu nome seria a publicação em Barcelona, também no ano posterior à morte do poeta, do livro intitulado Poemas póstumos. Neste caso, sendo bancado por um grupo de amigos mas editado, de fato, por dois deles, Juan Más y Pi e Marcelino del Mazo, igualmente com o apoio irrestrito do irmão do poeta, Julio Carriego. Como esse volume reunia não só as composições ainda não publicadas em livro por Carriego mas, também, todos os poemas de $\mathrm{Mi}$ sas herejes, essa edição de 1913 acabou se transformando, para aproximar do caso de Cesário, numa espécie de O Livro de Evaristo Carriego. Reuniu-se nele toda a produção poética conhecida do autor argentino, cerca de 107 poemas, acrescido de 4 outros posteriormente descobertos e agregados nas reedições.

Outras identidades porventura encontradas seriam mais da ordem de uma sociologia da literatura, ou seja, dizendo respeito ao típico ambiente literário 
das últimas décadas do século XIX e a primeira do século XX, ou até, digamos, a eclosão da guerra de 1914. Período que poderíamos chamar, com alguma liberdade, de uma Belle Époque literária que teve, como se sabe, Paris como o grande modelo, em todos os sentidos: literários, críticos, editoriais, comportamentais etc... Foi um período que recebeu inúmeras denominações, quando começaram a abundar os "ismos": realismo, naturalismo, parnasianismo, seguidos pelo simbolismo, decadentismo etc... Ou seja, é todo um período, cerca de 30 ou 40 anos, posto entre a grande escola do Romantismo e a chegada das chamadas vanguardas históricas. De uma perspectiva estritamente cronológica, Cesário posiciona-se no início desse período, ficando Carriego já às portas do seguinte, o que poderia distanciá-los bastante do ponto de vista estético. No entanto, não é o que acontece, pelo menos por dois motivos, além daquele apontado no início.

O primeiro diz respeito a Cesário, que, como bem se sabe, adiantou-se muito em relação à sua época. Principalmente se pensarmos em termos da lírica portuguesa, ainda presa então a um modo romântico ou tardo-romântico. Esse um dos motivos, aliás, do quase desconhecimento de sua obra enquanto viveu. Suas composições eram claramente antecipatórias daquilo que só iria se instituir com a chegada das vanguardas. No caso português, principalmente, Pessoa, Sá-Carneiro e Almada Negreiros. Uma série de características fizeram com que a obra de Cesário tivesse que esperar o seu "tempo de recepção", vamos chamá-lo assim. Apenas como exemplo, veja-se o seu desabafo para o amigo Antonio Papança, em carta de 29 de agosto de1880:

Ah! Quanto eu ia indisposto contra tudo e contra todos! Uma poesia minha, recente, publicada numa folha bem impressa, limpa, comemorativa de Camões, não obteve um olhar, um sorriso, um desdém, uma observação! Ninguém escreveu, ninguém falou, nem num noticiário, nem numa conversa comigo; ninguém disse bem, ninguém disse mal. (VERDE, 2006, p.189).

Tratava-se, nada mais nada menos, do poema "O sentimento de um Ocidental", a obra-prima de Cesário Verde e um dos grande poemas modernos, em qualquer língua.

O segundo motivo que irá aproximar os dois poetas, apesar da distância temporal, é que Carriego estará operando, naquele início do século XX, uma 
espécie de volta a um texto mais afeito ao estilo realista, direto, um retorno ao cotidiano, à expressão simples e vulgar. Estava reagindo aos excessos de uma literatura fin-du-siècle marcada pelo artificialismo, pelos temas exóticos (cisnes, fontes, marquesas e quejandos) e por um distanciamento da vida real de todos os dias levado ao paroxismo. O próprio Carriego, como já dito, escreveu seus primeiros poemas neste ambiente rarefeito e aristocratizante. Mas irá encontrar a sua VOz, como toda a crítica sempre apontou, ao descer dessa "torre ebúrnea" para as ruas. No seu caso específico e concreto, para as ruas de Palermo, um bairro em plena expansão de uma cidade que crescia a olhos vistos, impulsionada, em especial, pelo que ficou conhecido como sendo um “aluvião imigratório". Não há nada de hiperbólico na afirmação. A imigração para a "gran capital del Sud" no período foi uma das maiores já registradas e, naquela etapa histórica, só menor do que a que se dirigia para Nova Iorque.

Assim, tanto Cesário quanto Carriego se mostraram sensíveis às enormes modificações que estavam ocorrendo com suas cidades. Ambos se colocaram ao rés-do-chão, ambos, baudelaireanamente, se misturaram ao "turbilhão da rua". Embora, como já vimos, um no centro da cidade, outro na periferia. Os dois valorizaram sobremodo aquilo que seus sentidos perceberam. Como se dizia antigamente, para ambos os poetas "o mundo exterior existia". Por isso que mais de um comentador falou em "poesia realista" ao analisar suas obras. Dessa forma, há uma grande semelhança no que diz respeito ao caráter realista dos poemas aqui considerados. Como se sabe, tal viés não costuma ser muito frequente na poesia lírica, e esse é o principal motivo que me leva a comparar os dois poetas.

Calcados nos principais comentadores que se ocuparam desses autores, principalmente ao longo do século XX, podemos acrescentar, como uma espécie de corolário à principal característica do "realismo poético", várias outras. Sem indicar referências e pensando em Cesário Verde e Evaristo Carriego indistintamente, podemos dizer que se trata de uma poesia que visa a uma "valorização dos sentidos", que "aguarda a sua inspiração deixando-se absorver pelo real, pela vida das formas materiais e concretas". Daí "a grande maioria de seus poemas serem ao ar livre". "O seu 'modo poético' é atingido, paradoxalmente, graças a um 'modo prosaico'. O autor criou uma poesia do concreto, do vulgar, do cotidiano". Os quadros poéticos, os tableaux, "foram criados sobre modelos próximos", seja no espaço, seja no tempo. Isto é, "não se constituiram, pri- 
mordialmente, como poesia da memória”, como é tão comum na lírica. Pelo contrário, deu-se uma primazia total ao presente, ao aqui e agora. Também “alargou o âmbito do poético à representação pictórica das pessoas e das coisas humildes, apenas com o mérito da sua existência sensível.(...) Ensinou a poesia de respirar, de caminhar, de ver com amor, ingenuamente, sem prevenções, tudo quanto a vida nos oferece". "Demonstrou que a poesia anda esparsa pelos seres e pelas coisas habitualmente considerados prosaicos; a questão é ter olhos para ver e sensibilidade para sentir. Abriu à poesia as portas da vida e nela entraram os ruídos, os cheiros e a linguagem da rua".

Todas essas afirmações foram feitas visando à obra de Cesário Verde, mas poderiam muito bem serem trasladadas para a de Carriego. Claro que, aqui e ali, pode haver alguma discordância, seja em relação a Carriego, seja em relação ao próprio Cesário. Mas basta ler o conjunto de poemas urbanos desses autores para percebermos o quanto eles se aproximam. A mesma coisa poderia ser feita tomando-se, agora, a crítica carreguiana, mas seria desnecessário, tanto por economia textual quanto pelo fato de serem muito evidentes as identidades entre as duas poéticas no que diz respeito ao seu caráter realista.

Melhor seria nos encaminharmos para algumas diferenças, de não menor interesse. Pois, se o objeto de imitação aqui considerado - a cidade moderna - é o mesmo ou muito semelhante, as diferenças no modo de imitação são flagrantes, mesmo que dentro do que podemos chamar de um "realismo lírico", cujas características gerais foram elencadas acima.

A primeira diferença que cabe destacar diz respeito à topografia urbana. Carriego dirigiu toda a sua atenção - e de forma exclusiva - para as zonas periféricas da cidade, as chamadas orillas de Buenos Aires. A seção "El alma del subúrbio", do livro Misas herejes, abre com o poema de mesmo título, uma espécie de panorama de um dia no subúrbio, da manhã até a noite. Trata-se de uma composição relativamente longa (56 versos), onde o autor introduz temas e personagens que serão trabalhados mais particularizadamente nos 10 poemas seguintes da seção: "La viejecita", "El guapo", "En el barrio", "Residuo de fábrica", entre outros. Apenas como exemplo, vejamos as primeiras estrofes desse poema introdutório:

El gringo musicante ya desafina

En la suave habanera provocadora, 
Cuando se anuncia a voces, desde la esquina

"el boletín - famoso - de última hora".

Entre la algarabia del conventillo,

Esquivando empujones pasa ligero,

Pues trae noticias, uno que otro chiquillo

Divulgando las nuevas del pregonero.

En medio a la rueda de los marchantes,

El heraldo gangoso vende sus hojas ...

Donde sangran los sueltos espeluznantes

De las acostumbradas crónicas rojas.

(CARRIEGO, 1999, p.82)

Na sequência do poema vão entrando em cena os demais tipos do bairro: o operário, a costureira, o jogador, o dançarino de tango, a moça tuberculosa, o vigilante etc... Ao final da composição, já noite fechada, retorna aquele "gringo musicante" presente na abertura, pela manhã. Temos, assim, a síntese de um dia no subúrbio, visto de forma clara e objetiva. Trata-se de um tableaux do tipo baudelaireano voltado para o arrabal, no caso um tableaux palermitano. O hoje cosmopolita bairro de Palermo tem nesse poema, pode-se dizer, a sua certidão de nascimento do ponto de vista simbólico.

Já no caso de Cesário, se não de forma exclusiva, grande parte de sua atenção está voltada para as zonas centrais de Lisboa. O poeta nos joga no centro nervoso de uma cidade moderna, tal como ocorre no início do seu mais célebre poema, "O sentimento de um Ocidental":

Nas nossas ruas, ao anoitecer,

Há tal soturnidade, há tal melancolia,

Que as sombras, o bulício, o Tejo, a maresia

Despertam-me um desejo absurdo de sofrer.

O céu parece baixo e de neblina,

O gás extravasado enjoa-me, perturba;

$\mathrm{E}$ os edifícios, com as chaminés, e a turba,

Toldam-se duma cor monótona e londrina. 
Batem os carros d'aluguer, ao fundo,

Levando à via férrea os que se vão. Felizes!

Ocorrem-me em revista exposições, países:

Madrid, Paris, Berlim, S.Petersburgo, o mundo!

(VERDE, 2006, p.131)

A rigor, tanto num caso como no outro, a referencialidade está apenas implicitamente colocada para o leitor, ou seja, depende em grande parte das informações que estão fora do texto. Assim, no caso do poema carreguiano, sabemos pelo título tratar-se de um subúrbio, mas dependemos de outras fontes para nos inteirarmos de que se trata de subúrbio de uma grande cidade em processo de expansão e mais informações ainda para sabermos que corresponde ao bairro de Palermo em Buenos Aires.

Algo semelhante ocorre com o poema de Cesário Verde, embora seja quase impossível a um leitor minimamente informado não identificar logo a capital portuguesa. Mas é claro que tudo isso é de menor importância. O que interessa é perceber que a agitação e o movimento apresentados nos dois poemas em questão são de caráter bem diversos. Um diz respeito a uma vida ainda comunitária, composta de vizinhos, de trocas afetivas, sejam positivas ou negativas e experiências compartilhadas:

Las comadres del barrio, juntas, comentan

$\mathrm{Y}$ hacen filosofía sobre el destino ...

Já no caso de Cesário o que temos é mais uma agitação nervosa, típica dos centros metropolitanos:

Vazam-se os arsenais e as oficinas;

Reluz, viscoso, o rio, apressam-se as obreiras;

E num cardume negro, hercúleas, galhofeiras,

Correndo com firmeza, assomam as varinas.

É importante destacar que Carriego tinha à sua disposição uma cidade de proporções bem maiores do que dispunha Cesário, uma Lisboa que não havia alcançado ainda os 200 mil habitantes, enquanto a Buenos Aires do início 
do século já tinha ultrapassado há muito um milhão. Ocorre é que Carriego, embora freqüentador do Centro e participante ativo da já intensa vida cultural portenha, optou por representar o bairro onde morava. O crítico Leoncio Gianello considera que Carriego se posicionava "entre las luzes del centro y las penumbras de los barrios humildes" (GIANELLO, 1954, p.9). Roberto Giusti, também crítico, e próximo ao poeta argentino, lembrava que, "hombres del centro, le escuchábamos encantados, como si nos contase fábulas de un lejano y extraño país". (GIUSTI, 1927, p. 20)

Esses e outros depoimentos nos esclarecem muito sobre certos procedimentos e determinadas escolhas decisivas, além de originais, de Carriego. Algo diferente de Cesário (pelo que se pode deduzir das cartas conhecidas e das informações passadas pelos biógrafos do poeta português), Carriego gozou de uma aceitação muito grande no seu meio literário e obteve a admiração daqueles "hombres del centro". Na verdade, além da admiração, constituiu-se em efetiva liderança de um dos grupos principais que frequentavam o mais destacado cenáculo da época na capital portenha, o café Los imortales, como ficou conhecido.

Portanto, sua opção pelas "margens" da cidade não deve ser considerada como algo que tenha sido imposto ao provinciano de Entre Rios por um talvez hostil meio metropolitano, pelo contrário. O motivo devia estar em outro lugar, e uma das hipóteses mais interessantes a respeito nos foi dada por Juan Carlos Ghiano:

Mientras las calles del centro cada jornada se parecían más a las de las grandes capitales europeas, las del barrio donde vivía Carriego se quedaban en un esquema quasi provinciano, permitiendo al poeta la añoranza de la casi desconocida ciudad de su nascimiento, y también de La Plata, donde pasó años infantiles. (GHIANO, 1964, p.16)

A observação de Ghiano, vista de uma perspectiva do mundo globalizado de hoje, é notável. É como se Carriego, de origem provinciana, intuitivamente, tivesse "estacionado" nas orillas de Buenos Aires. Como se permanecesse, em essência, no que Borges chamaria de o "indefinível arrabalde", querendo significar com isso um espaço que não é mais campo mas ainda não é propriamente cidade. Sub-urbe, subúrbio, correspondendo exatamente a um 
entre-lugar, para lembrar o conhecido conceito de Silviano Santiago. Mais interessante ainda, no caso, parece ser a consideração de Capdevilla:

Así, en Carriego, no es la ciudad, la metrópoli, lo que cobra conciencia poética de sí; es el barrio. La ciudad ha crecido tanto y de manera tan desmesurada que su unidad se ha roto. Existen Palermo, la Boca, Flores, el Centro. Buenos Aires, no. (CAPDEVILLA, 1944, p. XVI)

O comentador está se referindo a um costume bastante enraizado em Buenos Aires, qual seja, de uma constituição da identidade a partir do bairro, ou de uma determinada zona da cidade e que costuma ou costumava ser considerada pelos habitantes como uma verdadeira patria chica. Creio que a expressão ficou conhecida mundialmente graças, principalmente, a Borges, que a utilizou em vários momentos. Mas é uma expressão e, mais que uma expressão, uma idéia, que se difundiu pela cultura argentina a partir de um determinado momento histórico, provavelmente em torno de 1900.

É claro que Carriego está profundamente vinculado a tudo isso. Beatriz Sarlo afirma: "Carriego se incorpora a esse panorama com su aporte fundamental: el barrio". (SARLO, s.d., p. 772). De fato, há um consenso solidamente estabelecido que atribui a Carriego o título de o poeta do arrabal portenho, mesmo entre aqueles que o estigmatizam como poeta "menor". Ninguém discute esse seu caráter pioneiro. Todos concordam que ele efetivamente "inventou" poeticamente o subúrbio de Buenos Aires.

Mas a questão que interessa aqui não é de precedência e, sim, refletir sobre esse deslocamento ou esse deslizamento a que Carriego submete a sua representação da cidade. Vários críticos apontaram em relação a Cesário o caráter ambíguo de sua relação com a cidade moderna e estão corretos. Há, visível, uma tensão não resolvida em muitos dos seus versos relacionados com a experiência urbana. Há um fascínio misturado a uma rejeição. Um comentador chega a falar numa "visão do Inferno" em relação a "O sentimento de um Ocidental". Isso tudo pode ser verdade, mas também é visível em muitos pontos e talvez mais ainda numa tomada de conjunto desse e de outros poemas de Cesário, um encantamento do "eu lírico" pela matéria que trata. Essa irresolução, essa tensão não resolvida, como dito há pouco, talvez confira ao texto do poeta português um charme muito próprio, aproximando-o mais de 
Baudelaire, conforme as análises que Marshall Berman fez do poeta francês e, por espelhamento, dos próprios escritos parisienses de Benjamin:

Os escritos parisienses de Benjamin constituem uma performance notavelmente dramática, surpreendentemente similar ao Ninotchka de Greta Garbo. Seu coração e sua sensibilidade o encaminharam de maneira irresistível para as luzes brilhantes da cidade, as belas mulheres, a moda, o luxo, seu jogo de superficies deslumbrantes e cenas grandiosas; enquanto isso, sua consciência marxista esforçou-se por mantê-lo a distância dessas tentações, mostrou-lhe que todo esse mundo luminoso é decadente, oco, viciado, espiritualmente vazio, opressivo em relação ao proletariado, condenado pela história. (BERMAN, 1986, p.142)

Embora não tivesse Cesário nenhum proletariado a defender, nem mesmo uma idéia de proletariado, é visível em muitos de seus versos uma identificação de fundo com as questões colocadas por Berman. Mas talvez mais produtivo fosse o caso de se pensar as diferentes estratégias utilizadas pelos autores no âmbito do conhecido conceito benjaminiano de experiência. Mais propriamente no âmbito da erfharung e da erlebnis, conforme a rica polarização do crítico alemão (BENJAMIN, 1986, p.197-221). Retomo Capdevilla: "La ciudad há crescido tanto y de forma tan desmesurada que su unidad se ha roto. Existen Palermo, la Boca, Flores, el Centro. Buenos Aires, no". Cabe a pergunta: até que ponto a solução barrial, a criação de uma patria chica, não correspondeu, no caso da cultura portenha, a uma defesa, a uma forma de manutenção das relações comunitárias, próximas, de caráter mais emotivo, comprometidas no âmbito puramente metropolitano, como tão bem argumentou o sociólogo Georg Simmel, no seu ensaio de 1902, intitulado "A metrópole e a vida mental", onde lemos:

Assim, o tipo metropolitano de homem - que, naturalmente, existe em mil variantes individuais - desenvolve um órgão que o protege das correntes e discrepâncias ameaçadoras de sua ambição externa, as quais, do contrário, o desenraizariam. Ele reage com a cabeça, ao invés de com o coração. (SIMMEL, 1979, p.12)

Para concluir essa primeira e breve aproximação entre esses dois poetas, não poderíamos deixar de falar de uma característica marcante, senão mesmo 
definidora, de todos os poetas urbanos. Refiro-me ao caráter deambulatório dessa poesia. Depois dos tão divulgados ensaios baudelaireanos de Benjamin, seria tentador caracterizar os dois poetas como flâneurs. E não estaríamos errados, principalmente no que diz respeito ao sujeito lírico dos poemas de Cesário Verde. Mas convém lembrar que, por mais rica e interessante que seja tal figura, o flâneur é apenas um tipo particular no âmbito deambulatório. Ou seja, há formas e formas de deambular. Seja como for, o certo é que os dois poetas, ao que tudo indica, gostavam muito de caminhar pelas ruas de sua cidade, e mais de um crítico chegou a apontar o ritmo andante dos versos aqui considerados. No caso de Carriego o fato é confirmado por vários depoimentos de seus contemporâneos. Mas convém apontar uma diferença significativa entre ambos. Cesário aproxima-se mais daquele "homem das multidões", do conhecido conto de Poe, tão bem utilizado por Benjamin nos seus estudos sobre Baudelaire. Há algo daquela nervosidade já apontada aqui nos deslocamentos constantes do "eu lírico" cesarino, aquele permanente caminhar sem nunca chegar que encontramos em alguns poemas; aquela ânsia, aquela angústia misturada com um fascínio pela cidade moderna que ia então se constituindo em terras portuguesas.

Nada disso encontramos em Carriego, pelo contrário. Não temos aqui aquele ritmo típico de uma metrópole. Isso numa Buenos Aires que, como já dito, era bem maior e mais dinâmica do que a Lisboa de Cesário Verde. Ocorre que o poeta argentino se punha longe das "luzes da cidade". Daí o seu ritmo mais pausado, mais suburbano, o que introduz uma grande diferença em relação aos poemas de Cesário. Além disso, com Evaristo Carriego andamos não só pelas ruas, praças e esquinas do bairro, mas entramos dentro das suas casas, convivemos com seus moradores, observamos suas ações, principalmente escutamos suas vozes. Vejamos dois exemplos, para explicitar melhor o que está sendo tratado, começando por alguns versos de Cesário, retirados do poema "Contrariedades":

Sentei-me à secretaria. Ali defronte mora

Uma infeliz, sem peito, os dois pulmões doentes;

Sofre faltas de ar, morreram-lhe os parentes

E engoma para fora. 
Pobre esqueleto branco entre as nevadas roupas!

Tão lívida! O doutor deixou-a. Mortifica.

Lidando sempre! E deve a conta na botica!

Mal ganha para sopas ...

(VERDE, 2006, p.131)

Agora versos de Carriego, extraídos de "Resíduo de fábrica":

Hoy ha tosido mucho. Van dos noches

Que no puede dormir; noches fatales,

En esa oscura pieza donde pasa

Sus más amargos dias, sin quejarse.

El taller la enfermó, y así, vencida

En plena juventud, quizás no sabe

De una hermosa esperanza que acaricie

Sus largos sufrimientos de incurable.

(CARRIEGO, 1999, p.92)

Já aqui temos uma intimidade maior, nos sentimos dentro da casa, ainda, porém, como observadores. Mas se escolhermos, por exemplo, o poema "Sola", do seu segundo livro, La canción del barrio, nos sentiremos verdadeiramente "em casa", como que participando daquela família ali representada. Ali e em todos os outros 18 poemas da seção: trata-se da mesma família, sem dúvida. Eis a segunda das cinco estrofes:

Bueno. Por fin estás sola ... No hay nadie,

Todas las amigas se fueron

$\mathrm{Y}$ se halla en silencio la casa.

La abuela descansa, y los chicos

En el distante comedor

Juegan despacio, sin dar gritos.

Apenas si afuera, en la calle,

Persiste un rumor apagado

De voces. Estás sola, sola, 
En la paz grave de tu cuarto.

(CARRIEGO, 1999, p.164)

Neste e nos demais poemas da seção iremos encontrar aquele estilo conversado do portenho, que o jovem Borges tanto admirava e que foi um dos motivos que o fez aproximar-se de Carriego, "permanente conversador que conocí en mi infancia, en los domingos de la calle Serrano [Palermo] (BORGES, 1994, p.28). O caráter de oralidade para o qual foi se dirigindo a poesia do autor de La canción del barrio tornou-a antecipatória de todo um estilo poético que iria se propagar pelo século XX, e que só mais recentemente a crítica carreguiana tem explicitado e avaliado na sua real importância. E nessa questão da oralidade Carriego e Cesário se separam. O "eu lírico" do primeiro se pôs, cada vez mais, a dialogar, transmudando-se em inúmeras vozes do bairro, numa "conversa infinita" entre ... vizinhos. Muito a propósito, Ignácio Xurxo recorda, num comentário à obra do poeta do subúrbio portenho, que "según Sartre, solo se puede escribirse para Dios o para los vecinos" (CARRIEGO, 1999, p.248). E vizinhos como esses, conforme refere o amigo Marcelo del Mazo, "no saben cómo agradecer al muchacho la divulgación de su existencia" (MAZO, 1937, p.202). De fato, a poesia de Carriego foi daquelas que podia ser lida pelos vizinhos do poeta, e por isso estabeleceu um alto grau de comunicação. Talvez não houvesse revolução maior na lírica contemporânea se isso viesse a acontecer de forma generalizada. Mas os tempos, decididamente, não estão para isso. Estão mais para um "eu lírico" do tipo de Cesário, que se mantém firme no seu monólogo, na sua solidão, no seu isolamento, e certamente por isso representa muito mais a cidade moderna.

\section{Referências Bibliográficas}

BORGES, Jorge Luis. Carriego y el sentido del arrabal. In: El tamaño de mi esperanza. Barcelona:Seix Barral, 1994.

BENJAMIN, Walter. Magia e técnica, arte e política. 2 ed. São Paulo:Brasiliense, 1986. Obras Escolhidas.

BERMAN, Marshall. Tudo que é sólido desmancha no ar. São Paulo:Cia.das Letras, 1986. CAPDEVILLA, Arturo. Evaristo Carriego en dos estampas. In: CARRIEGO, Evaristo. Poesías completas. Buenos Aires:Jackson, 1944. 
CARRIEGO, Evaristo. Obra completa. Org. Marcela Ciruzzi. Buenos Aires:Corregidor, 1999.

GIANELLO, Leoncio. Carriego y su mensaje perdurable. In: CARRIEGO, Evaristo. Cuentos y otras páginas. Santa Fé:Castelví, 1954.

GIUSTI, Roberto. Veinte años de vida. In Nosotros, Buenos Aires: (219-220): 20, 1927.

GUIANO, Juan Carlos. Evaristo Carriego. In: CARRIEGO, Evaristo. Poesías. Buenos Aires:Fabril Editora, 1964.

MAZO, Marcelo del. Evaristo Carriego. In Nosotros, Buenos Aires: (19): 202, oct. 1937.

SALAS, Horacio. La poesía de Buenos Aires. Buenos Aires:Pleamar, 1968.

SARLO, Beatriz. La poesía en el avance del siglo. In: Capitulo. La historia de la literatura argentina. Fascículo 33. Buenos Aires:Centro Editor de América Latina, s.d.

SIMMEL, Georg. A metrópole e a vida mental. In: VELHO, Otávio Guilherme. (Org.) O fenômeno urbano. São Paulo:Zahar, 1979.

VERDE, Cesário. Obra poética integral de Cesário Verde (1855-86). Org. Ricardo Daunt. Lisboa:Landy, 2006. 